Check for updates

Cite this: RSC Adv., 2019, 9, 5453

\section{VUV spectroscopy of an electron irradiated benzene : carbon dioxide interstellar ice analogue}

\author{
Rachel L. James, (D)*a Nykola C. Jones, (D) b Søren V. Hoffmann (iD) ${ }^{\mathrm{b}}$ \\ and Anita Dawes (iD ${ }^{a}$
}

\begin{abstract}
We present the first vacuum ultraviolet spectroscopic study of an interstellar ice analogue of a $1: 100$ benzene $\left(\mathrm{C}_{6} \mathrm{H}_{6}\right)$ : carbon dioxide $\left(\mathrm{CO}_{2}\right)$ mixture which has been energetically processed with $1 \mathrm{keV}$ electrons. We have exploited the fact that benzene has a relatively high photoabsorption cross section in the vacuum ultraviolet region to study this dilute mixture of benzene. Before irradiation with $1 \mathrm{keV}$ electrons, we observed that the benzene electronic transition bands in the $\mathrm{C}_{6} \mathrm{H}_{6}: \mathrm{CO}_{2}$ mixture exhibits a blueshift in band position towards energies observed in the gas-phase compared with that of pure, amorphous benzene and we have attributed this to a matrix isolation effect. After irradiation, a lowering in intensity of both the carbon dioxide and benzene electronic transition bands was observed, as well as the formation of the small irradiation product, carbon monoxide. A residue was obtained at $200 \mathrm{~K}$ which showed characteristic features of the benzene electronic transition of ${ }^{1} \mathrm{E}_{1 \mathrm{u}} \leftarrow{ }^{1} \mathrm{~A}_{1 \mathrm{~g}}$, but with additional structure suggesting the formation of a benzene derivative.
\end{abstract}

Received 18th January 2019 Accepted 3rd February 2019

DOI: $10.1039 / c 9 r a 00462 a$

rsc.li/rsc-advances gas- $^{8}$ or solid-phase which are more likely in low temperature, molecular cloud environments. Within our own Solar System, PAHs and benzene derivatives have been detected on some Saturnian moons, ${ }^{9}$ interplanetary dust grains ${ }^{\mathbf{1 0}}$ and meteorites. In fact, some of the PAHs and benzene derivatives detected in meteoritic materials show deuterium enrichment indicating that the formation origin of these molecules may be from molecular cloud environments. ${ }^{11}$

Although PAHs, benzene and its derivatives have not been directly identified in the solid-phase, which is most likely due to their weak infrared absorption features overlapping with intense ice absorption bands, they are believed to be incorporated into icy mantles around interstellar dust grains or operate as nucleation sites for the condensation of other species. ${ }^{12}$ Within molecular clouds, the icy mantles of interstellar dust grains may be subjected to energetic processing (protons, secondary UV photons or secondary electrons) which could induce molecular synthesis within the ice. Several experimental studies have looked at the formation of PAHs or benzene derivatives within interstellar ice analogues. ${ }^{\mathbf{1 3 - 1 5}}$ In particular, aromatic molecules with the carboxylic acid moiety $(-\mathrm{COOH})$ have been studied because of their role as precursors to amino acids with non-aromatic carboxylic acids detected in the ISM in the form of formic acid $(\mathrm{HCOOH})^{16}$ and acetic acid $\left(\mathrm{CH}_{3}\right.$ $\mathrm{COOH}) .{ }^{17}$ Carboxylic acids with varying degrees of complexity have also been detected in the Tagish Lake, ${ }^{18-20}$ Murchison ${ }^{21,22}$ and Orgueil ${ }^{22,23}$ carbonaceous meteorites.

In this paper we investigate the energetic processing of a dilute mixture of benzene in $\mathrm{CO}_{2}$, as an interstellar ice analogue, with $1 \mathrm{keV}$ electrons using vacuum ultraviolet (VUV)
${ }^{a}$ School of Physical Sciences, The Open University, Walton Hall, Milton Keynes, UK. E-mail: Rachel.James1@open.ac.uk; Fax: +44(0) 1908 654192; Tel: +44(0) 1908 332012

${ }^{b}$ ISA, Centre for Storage Ring Facilities, Department of Physics and Astronomy, Aarhus University, Ny Munkegade 120, DK-8000 Aarhus C, Denmark 
spectroscopy. While mid-IR spectroscopy is the more commonly used in situ laboratory technique for investigating the structure and composition of interstellar ices, and any changes upon energetic processing, this is the first time that VUV spectroscopy has been used to study the benzene : $\mathrm{CO}_{2}$ system. With VUV spectroscopy we can take advantage of the fact that benzene has appreciatively high photoabsorption cross sections due to strong electronic $\pi \rightarrow \pi^{*}$ transitions compared to that of other interstellar ice constituents such as $\mathrm{H}_{2} \mathrm{O}$ and $\mathrm{CO}_{2}$. For example, cross sections of benzene at wavelengths $<200 \mathrm{~nm}$ reach 50 $\mathrm{Mb}^{24}$ which is almost 40 times more intense compared to that of the $\mathrm{CO}_{2}$ peak cross section of around $1.3 \mathrm{Mb} .^{25}$ In contrast, the mid-IR band strength ( $A$-value) of the strongest vibrational transition of solid benzene, the $\mathrm{C}-\mathrm{C}$ stretch $\left(v_{19}\right)$, is $1.4 \times$ $10^{-18} \mathrm{~cm}$ per molecule ${ }^{26}$ which is approximately 90 times less intense compared to the $\mathrm{C}-\mathrm{O}$ stretch $\left(v_{3}\right)$ of $\mathrm{CO}_{2}$ with a band strength of $1.3 \times 10^{-16} \mathrm{~cm}$ per molecule. ${ }^{27}$ This makes VUV spectroscopy a potentially more favourable region of the electromagnetic spectrum to study very dilute mixtures of benzene in ice matrices (e.g. benzene and water). In this paper we present the results of the first experimental study using VUV spectroscopy to investigate an electron irradiated, $1: 100 \mathrm{C}_{6} \mathrm{H}_{6}: \mathrm{CO}_{2}$ mixture as an interstellar ice analogue.

\section{Experimental}

Experiments were carried out using The Open University's Portable Astrochemistry Chamber (PAC) attached to the AU-UV beamline at the ASTRID2 Synchrotron Facility in Aarhus, Denmark. ${ }^{28}$ This set-up has been used before for the investigation of condensed phase molecules and is described in detail elsewhere by Dawes et al. ${ }^{24}$ and only a brief description is given here.

The experiments were carried out at a base pressure of low $10^{-8}$ mbar. Benzene (anhydrous; Sigma-Aldrich, 99.8\% purity) was degassed via three freeze-pump-thaw cycles prior to use and pre-mixed with $\mathrm{CO}_{2}$ (Sigma-Aldrich, 99.995\% purity) in the gas line. The mixture was then vapour deposited onto a cold (20 K) $\mathrm{MgF}_{2}$ (Crystran) substrate held in a copper holder attached to a closed cycle helium cryostat (Sumitomo). VUV spectra were acquired in the range $120-340 \mathrm{~nm}$ with 0.05 to $1 \mathrm{~nm}$ wavelength step size depending on the width of the spectral features to be resolved. Absorbance spectra were calculated from the recorded incident and transmitted intensities as a function of wavelength (nm).

Film thickness was determined from in situ laser interferometry measurements from the use of a HeNe laser beam reflected off the substrate during deposition. Deposition rates were between 0.12 and $0.55 \mathrm{~nm} \mathrm{~s}^{-1}$ depending on the thickness of the ice being grown. The final thickness of the films were $349 \mathrm{~nm}$ for the unirradiated mixture and a $1.28 \mu \mathrm{m}$ for the irradiated mixture. For the unirradiated mixture a thinner ice was prepared to avoid saturation of the electronic transition bands, to allow for accurate band assignments and observe any changes in the band profiles upon annealing. A thicker ice was prepared for irradiation to ensure a sufficient quantity of products were formed for observation/monitoring and to ensure that the ice thickness was greater than the penetration depth of electrons so that there was no substrate effect. This thicker ice was grown in stages to confirm that no thickness-dependent effects were present until saturation of the peaks was observed.

The mixture was irradiated with $1 \mathrm{keV}$ electrons (Kimball Physics FRA-2X1-2/EGPS-1011A) with a current of $10 \mu \mathrm{A}$ and the bombarded area was about $3.5 \mathrm{~cm}^{-2}$. The electron flux at the sample was approximately $1.77 \times 10^{13}$ electrons per $\mathrm{cm}^{2}$ per $\mathrm{s}$. After $180 \mathrm{~min}$ of irradiation this corresponded to a fluence of $1.91 \times 10^{17}$ electrons per $\mathrm{cm}^{2}$. A penetration depth of $40 \mathrm{~nm}$ for $1 \mathrm{keV}$ electrons was estimated using Monte Carlo simulations from the CASINO code. ${ }^{29}$

Samples were annealed gradually at a rate of $1 \mathrm{~K} \mathrm{~min}^{-1}$ by heating the sample using a Kapton heater and regulated with a temperature controller (Oxford Instruments). The samples were held at the required temperature for $2 \mathrm{~min}$ and then returned to base temperature $(20 \mathrm{~K})$ prior to measuring the spectra.

\section{Results and discussion}

From previous studies ${ }^{24,30}$ we know that when solid-phase benzene is diluted with amorphous solid water a blueshift in the electronic bands compared to that of pure benzene is observed. We therefore used an unirradiated control sample to characterise the $1: 100 \mathrm{C}_{6} \mathrm{H}_{6}: \mathrm{CO}_{2}$ mixture and any effects annealing might produce, the results of which are discussed in Section 3.1. In Section 3.2 we discuss the results of irradiating the $1: 100 \mathrm{C}_{6} \mathrm{H}_{6}: \mathrm{CO}_{2}$ mixture with $1 \mathrm{keV}$ electrons for $180 \mathrm{~min}$ and in Section 3.2.1 we discuss the results on the residue left at $200 \mathrm{~K}$.

\subsection{Characterisation of an unirradiated $1: 100 \mathrm{C}_{6} \mathrm{H}_{6}: \mathrm{CO}_{2}$ mixture}

3.1.1 The electronic structure of a $1: 100 \quad \mathrm{C}_{6} \mathrm{H}_{6}: \mathrm{CO}_{2}$ mixture at $20 \mathrm{~K}$. Fig. 1 shows the VUV photoabsorption spectrum of a $1: 100 \mathrm{C}_{6} \mathrm{H}_{6}: \mathrm{CO}_{2}$ mixture deposited at $20 \mathrm{~K}$ compared with spectra of a $1: 100 \mathrm{C}_{6} \mathrm{H}_{6}: \mathrm{H}_{2} \mathrm{O}$ mixture deposited at $24 \mathrm{~K},{ }^{30}$ pure benzene deposited at $24 \mathrm{~K}$ and gas-phase benzene. ${ }^{24}$ Two broad bands centred around 127 and $142 \mathrm{~nm}$ are due to $\mathrm{CO}_{2}$ and correspond to the ${ }^{1} \prod_{\mathrm{g}} \leftarrow{ }^{1} \sum_{\mathrm{g}}^{+}$and ${ }^{1} \Delta_{\mathrm{u}} \leftarrow{ }^{1} \sum_{\mathrm{g}}^{+}$transitions respectively. The higher energy ${ }^{1} \prod_{\mathrm{g}} \leftarrow{ }^{1} \sum_{\mathrm{g}}^{+}$transition exhibits vibronic structure the positions of which are in good agreement (to within $10 \mathrm{meV}$ ) with a study conducted by Mason et al. ${ }^{25}$ where pure $\mathrm{CO}_{2}$ was deposited at 20 K.

Three benzene bands in the $1: 100 \mathrm{C}_{6} \mathrm{H}_{6}: \mathrm{CO}_{2}$ mixture are observed in Fig. 1 and correspond to the ${ }^{1} \mathrm{E}_{1 \mathrm{u}} \leftarrow{ }^{1} \mathrm{~A}_{1 \mathrm{~g}},{ }^{1} \mathrm{~B}_{1 \mathrm{u}} \leftarrow$ ${ }^{1} \mathrm{~A}_{1 \mathrm{~g}}$ and ${ }^{1} \mathrm{~B}_{2 \mathrm{u}} \leftarrow{ }^{1} \mathrm{~A}_{1 \mathrm{~g}}$ transitions. The ${ }^{1} \mathrm{E}_{1 \mathrm{u}} \leftarrow{ }^{1} \mathrm{~A}_{1 \mathrm{~g}}$ transition is the most intense benzene band and it is blueshifted by $0.30 \mathrm{eV}$ from $191.8 \mathrm{~nm}(6.47 \mathrm{eV})$ in pure benzene to $183.2 \mathrm{~nm}(6.77 \mathrm{eV})$ in the $1: 100 \mathrm{C}_{6} \mathrm{H}_{6}: \mathrm{CO}_{2}$ mixture. The ${ }^{1} \mathrm{~B}_{1 \mathrm{u}} \leftarrow{ }^{1} \mathrm{~A}_{1 \mathrm{~g}}$ transition appears as a structured shoulder on the long wavelength side of the ${ }^{1} \mathrm{E}_{1 \mathrm{u}} \leftarrow{ }^{1} \mathrm{~A}_{1 \mathrm{~g}}$ transition (assignments are given in Table 1) and is again blueshifted compared to that of pure benzene. Interestingly the benzene band assignments for the 1:100 


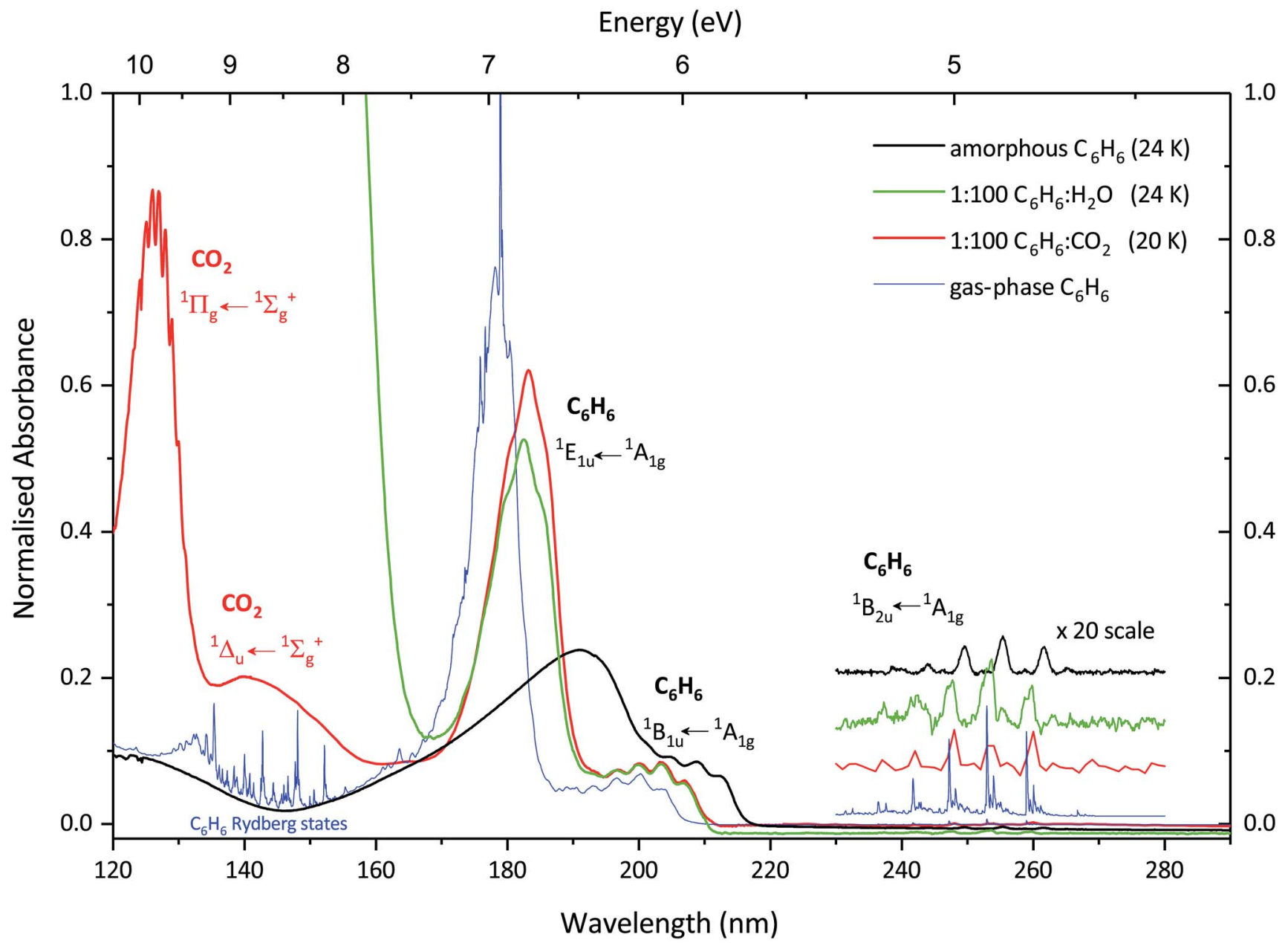

Fig. 1 VUV photoabsorption spectra of $1: 100 \mathrm{C}_{6} \mathrm{H}_{6}: \mathrm{CO}_{2}$ mixture deposited at $20 \mathrm{~K}$ (red) compared with pure, amorphous benzene deposited at $24 \mathrm{~K}$ (black), $1: 100 \mathrm{C}_{6} \mathrm{H}_{6}: \mathrm{H}_{2} \mathrm{O}$ mixture deposited at $24 \mathrm{~K}$ (green) and gas-phase benzene (blue) from ref. 24 and 30 . The band assignments and positions are summarised in Table 1 . The ${ }^{1} B_{2 u} \leftarrow{ }^{1} A_{1 g}$ vibronic bands between 230-270 nm have been scaled $x 20$ and offset for clarity. The spectra are normalised to the integrated area of the overlapping ${ }^{1} \mathrm{E}_{1 \mathrm{u}} \leftarrow{ }^{1} \mathrm{~A}_{1 \mathrm{~g}}$ and ${ }^{1} \mathrm{~B}_{1 \mathrm{u}} \leftarrow{ }^{1} \mathrm{~A}_{1 \mathrm{~g}}$ transitions of the $1: 100 \mathrm{C}_{6} \mathrm{H}_{6}: \mathrm{CO}_{2}$ mixture deposited at $20 \mathrm{~K}$.

$\mathrm{C}_{6} \mathrm{H}_{6}: \mathrm{CO}_{2}$ mixture are in good agreement with a $1: 100$ $\mathrm{C}_{6} \mathrm{H}_{6}: \mathrm{H}_{2} \mathrm{O}$ mixture. In the previous study by Dawes et al. ${ }^{30}$ several ratios $(1: 1,1: 10$ and $1: 100)$ of $\mathrm{C}_{6} \mathrm{H}_{6}: \mathrm{H}_{2} \mathrm{O}$ were studied and as the benzene was diluted, successive blueshifts from pure benzene were observed and attributed to a matrix isolation effect. Also, the $1: 100 \mathrm{C}_{6} \mathrm{H}_{6}: \mathrm{H}_{2} \mathrm{O}$ mixture showed

Table 1 Band assignments and positions of the main electronic and vibronic bands for benzene shown in Fig. 1 for a $1: 100 \mathrm{C}_{6} \mathrm{H}_{6}: \mathrm{CO}_{2}$ mixture deposited at $20 \mathrm{~K}$, annealed to $80 \mathrm{~K}$ and then $90 \mathrm{~K}$ compared with pure benzene at $24 \mathrm{~K}$ and gas-phase benzene from ref. 24 and 30 . The gas to solid energy shifts (in eV) are shown under headings ' $\mathrm{g}-\mathrm{s}$ '

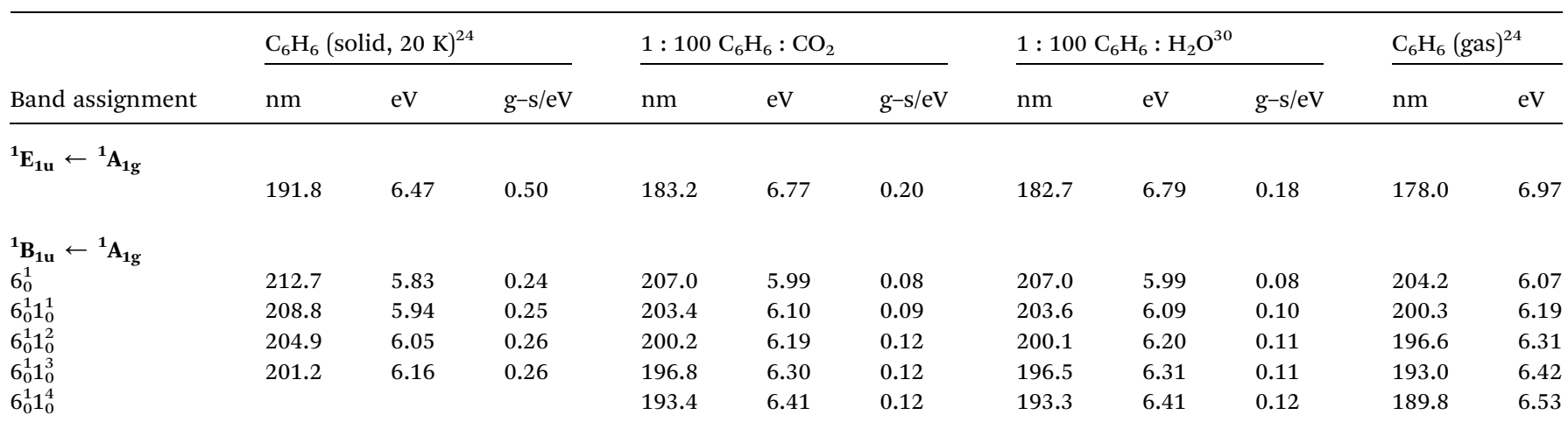


structure within in the ${ }^{1} \mathrm{E}_{1 \mathrm{u}} \leftarrow{ }^{1} \mathrm{~A}_{1 \mathrm{~g}}$ transition band which resembled the band profile of gas-phase benzene and was not observed in the less diluted benzene mixtures. This gas-phase like band profile is also observed in the $1: 100 \mathrm{C}_{6} \mathrm{H}_{6}: \mathrm{CO}_{2}$ mixture of the ${ }^{1} \mathrm{E}_{1 \mathrm{u}} \leftarrow{ }^{1} \mathrm{~A}_{1 \mathrm{~g}}$ transition band and further supports the theory of matrix isolation as a cause of the shifts observed in the electronic band rather than a solvent effect. While the vibronic peaks of the ${ }^{1} \mathrm{~B}_{2 \mathrm{u}} \leftarrow{ }^{1} \mathrm{~A}_{1 \mathrm{~g}}$ electronic transition are not completely resolved, the data is sufficient to suggest a blue shift in position towards energies observed in the gas-phase in a similar fashion to that of the $1: 100 \mathrm{C}_{6} \mathrm{H}_{6}: \mathrm{H}_{2} \mathrm{O}$ mixture.

3.1.2 The electronic structure of a $1: 100 \quad \mathrm{C}_{6} \mathrm{H}_{6}: \mathrm{CO}_{2}$ mixture annealed to 80,90 and $140 \mathrm{~K}$. Fig. 2 shows the VUV photoabsorption spectra of the $1: 100 \mathrm{C}_{6} \mathrm{H}_{6}: \mathrm{CO}_{2}$ mixture as it is annealed to 80,90 and $140 \mathrm{~K}$ corresponding to the temperature at which pure $\mathrm{CO}_{2}$ is crystalline ( $>80 \mathrm{~K}$ ), pure benzene begins to crystallise and pure $\mathrm{CO}_{2}$ desorbs (75-90 K), and, pure benzene desorbs $(140 \mathrm{~K})$. At $80 \mathrm{~K}$ the $\mathrm{CO}_{2}{ }^{1} \prod_{\mathrm{g}} \leftarrow{ }^{1} \sum_{\mathrm{g}}^{+}$and ${ }^{1} \Delta_{\mathrm{u}} \leftarrow{ }^{1} \sum_{\mathrm{g}}^{+}$transition bands are still present in the same position as that of spectra taken at $20 \mathrm{~K}$, albeit with lower intensity, and by $90 \mathrm{~K}$ they have disappeared due to desorption of $\mathrm{CO}_{2}$. At $80 \mathrm{~K}$ the ${ }^{1} \mathrm{E}_{1 \mathrm{u}} \leftarrow{ }^{1} \mathrm{~A}_{1 \mathrm{~g}}$ transition of benzene has lowered in intensity and the band profile is showing signs of the splitting characteristic of that of crystallisation of benzene. The ${ }^{1} \mathrm{~B}_{1 \mathrm{u}} \leftarrow$ ${ }^{1} \mathrm{~A}_{1 \mathrm{~g}}$ vibronic structure appears less well defined than at $20 \mathrm{~K}$ and may be due to desorption of $\mathrm{CO}_{2}$ which is also occurring at $80 \mathrm{~K}$. When the $\mathrm{CO}_{2}$ is fully desorbed at $90 \mathrm{~K}$ the ${ }^{1} \mathrm{E}_{1 \mathrm{u}} \leftarrow{ }^{1} \mathrm{~A}_{1 \mathrm{~g}}$ has shifted from $183.4 \mathrm{~nm}$ to $192.8 \mathrm{~nm}$ with a well defined splitting in the band ( $190.6 \mathrm{~nm}$ and $194.6 \mathrm{~nm}$ ) observed. Additionally the ${ }^{1} \mathrm{~B}_{1 \mathrm{u}} \leftarrow{ }^{1} \mathrm{~A}_{1 \mathrm{~g}}$ vibronic features have sharpened compared to that at $80 \mathrm{~K}$ and shifted to pure, crystalline benzene positions. ${ }^{24}$ At $140 \mathrm{~K}$ all the benzene has been removed from the substrate.

\subsection{Electron irradiation and subsequent annealing of a $1: 100 \mathrm{C}_{6} \mathrm{H}_{6}: \mathrm{CO}_{2}$ mixture}

After irradiating with $1 \mathrm{keV}$ electrons there is a noticeable difference in the spectrum compared to that of the unirradiated spectrum as shown in Fig. 3. The irradiation product carbon monoxide (CO) is observed via the vibronic structure of the $\mathrm{A}^{1} \Pi$ $\leftarrow \mathrm{X}^{1} \sum^{+}$transition, the assignments are shown in Table 2 and compared with pure CO and CO formed via VUV irradiation of $\mathrm{CO}_{2}$. Davydov splitting observed in the lower energy bands $(0,0-$ 3,0 ) of pure $\mathrm{CO}$ are not observed in $\mathrm{CO}$ formed from irradiation of electrons, consistent with that of the CO formed from VUV photons in a study by Cruz-Diaz et al. ${ }^{31}$ Additionally the vibronic bands have blueshifted compared to that of pure $\mathrm{CO}$, which is

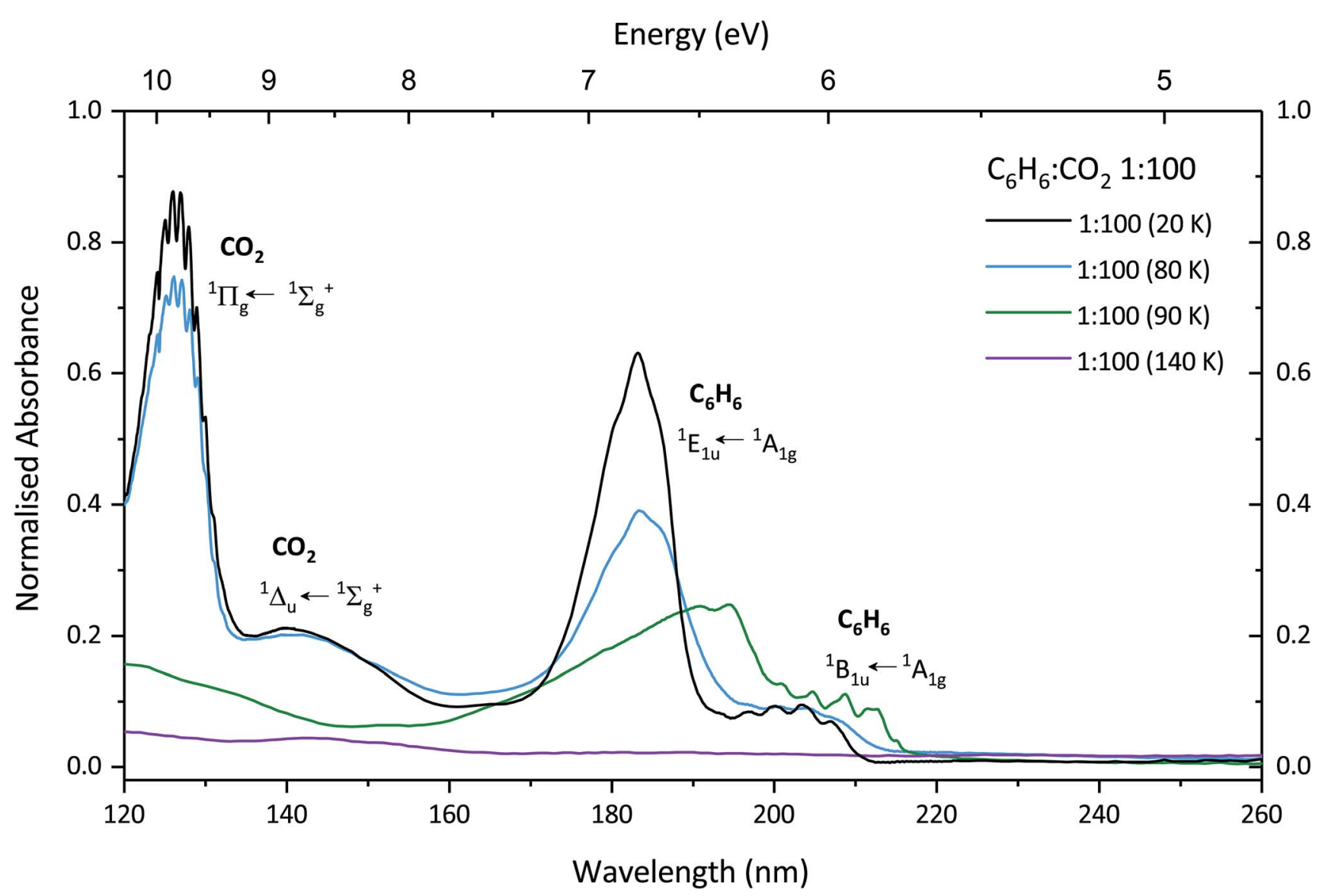

Fig. 2 VUV photoabsorption spectra of a $1: 100 \mathrm{C}_{6} \mathrm{H}_{6}: \mathrm{CO}_{2}$ mixture deposited at $20 \mathrm{~K}$ (black) and annealed to $80 \mathrm{~K}$ (blue), $90 \mathrm{~K}$ (green) and $140 \mathrm{~K}$ (purple). The spectra are normalised to the integrated area of the overlapping ${ }^{1} \mathrm{E}_{1 \mathrm{u}} \leftarrow{ }^{1} \mathrm{~A}_{1 \mathrm{~g}}$ and ${ }^{1} \mathrm{~B}_{1 \mathrm{u}} \leftarrow{ }^{1} \mathrm{~A}_{1 \mathrm{~g}}$ transitions of the $1: 100 \mathrm{C}_{6} \mathrm{H}_{6}: \mathrm{CO}_{2}$ mixture deposited at $20 \mathrm{~K}$. 


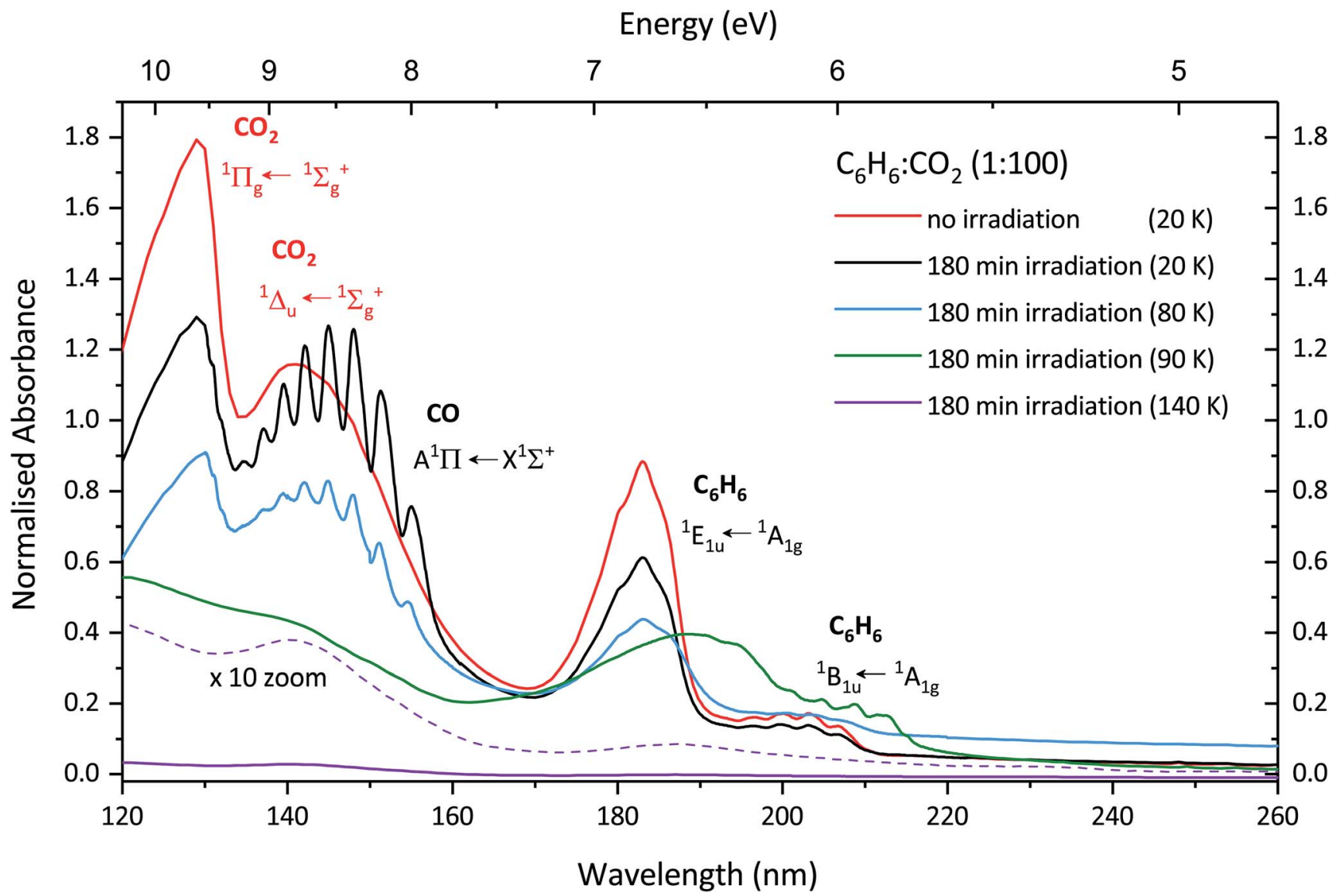

Fig. 3 VUV photoabsorption spectra of a $1: 100 \mathrm{C}_{6} \mathrm{H}_{6}: \mathrm{CO}_{2}$ mixture deposited at $20 \mathrm{~K}$ (red), irradiated for 180 min with $1 \mathrm{keV}$ electrons (black) and annealed to $80 \mathrm{~K}$ (blue), $90 \mathrm{~K}$ (green) and $140 \mathrm{~K}$ (purple). The purple dashed line shows the $140 \mathrm{~K}$ trace scaled $\times 10$. The spectra are normalised to the integrated area of the overlapping ${ }^{1} \mathrm{E}_{1 \mathrm{u}} \leftarrow{ }^{1} \mathrm{~A}_{1 \mathrm{~g}}$ and ${ }^{1} \mathrm{~B}_{1 \mathrm{u}} \leftarrow{ }^{1} \mathrm{~A}_{1 \mathrm{~g}}$ transitions of the $1: 100 \mathrm{C}_{6} \mathrm{H}_{6}: \mathrm{CO}_{2}$ mixture deposited at $20 \mathrm{~K}$.

also consistent with that of Cruz-Diaz et al. ${ }^{31}$ The ${ }^{1} \prod_{\mathrm{g}} \leftarrow{ }^{1} \sum_{\mathrm{g}}^{+}$ transition of $\mathrm{CO}_{2}$ is also present after irradiation but at lower intensity, which might be due to a combination of dissociation from electron irradiation and sputtering. The ${ }^{1} \Delta_{\mathrm{u}} \leftarrow{ }^{1} \sum_{\mathrm{g}}^{+}$transition of $\mathrm{CO}_{2}$ is not observable due to the overlapping $\mathrm{A}^{1} \Pi \leftarrow$ $\mathrm{X}^{1} \sum^{+} \mathrm{CO}$ band which has a much higher cross section. The ${ }^{1} \mathrm{E}_{1 \mathrm{u}}$ $\leftarrow{ }^{1} \mathrm{~A}_{1 \mathrm{~g}}$ and ${ }^{1} \mathrm{~B}_{1 \mathrm{u}} \leftarrow{ }^{1} \mathrm{~A}_{1 \mathrm{~g}}$ transitions of benzene are also present in the same position as the unirradiated benzene, albeit with lower intensity due to formation of products or sputtering.
Upon annealing to $80 \mathrm{~K}$ there is a further decrease in intensity of the ${ }^{1} \prod_{\mathrm{g}} \leftarrow{ }^{1} \sum_{\mathrm{g}}^{+}$transition of $\mathrm{CO}_{2}$ as it is close to the desorption temperature of $\mathrm{CO}_{2}$. At $80 \mathrm{~K}$ it is expected that the CO would have desorbed, as pure CO desorbs between 28-36 K depending on the original deposition temperature (a lower deposition temperature will allow $\mathrm{H}_{2}$ to vapour deposit on the surface which can stimulate desorption at lower temperatures). ${ }^{32}$ However, the $A^{1} \Pi \leftarrow X^{1} \sum^{+}$transition is still clearly observable although the intensity is lowered somewhat, with

Table 2 Band assignments and positions of the $\mathrm{CO} \mathrm{A}^{1} \Pi \leftarrow \mathrm{X}^{1} \sum^{+}$transition formed from a $1: 100 \mathrm{C}_{6} \mathrm{H}_{6}: \mathrm{CO}_{2}$ mixture irradiated by 1 keV electrons for 180 min and compared with pure CO taken from Mason et al. ${ }^{25}$ and CO formed from VUV photons in a $\mathrm{CO}_{2}$ matrix. ${ }^{31} \mathrm{Band}$ splitting is indicated by numbers in parenthesis

\begin{tabular}{|c|c|c|c|c|c|}
\hline \multirow{2}{*}{$\begin{array}{l}\text { Band assignment } \\
\left(v^{\prime}, v^{\prime \prime}\right)\end{array}$} & \multirow{2}{*}{$\frac{\text { Pure } \mathrm{CO}^{25}}{\mathrm{eV}}$} & \multicolumn{2}{|c|}{ This work } & \multicolumn{2}{|c|}{$\mathrm{CO}$ in $\mathrm{CO}_{2}$ matrix ${ }^{31}$} \\
\hline & & $\mathrm{nm}$ & $\mathrm{eV}$ & $\mathrm{nm}$ & $\mathrm{eV}$ \\
\hline 6,0 & 9.01 & 137.10 & 9.04 & 137.0 & 9.05 \\
\hline 5,0 & 8.88 & 139.60 & 8.88 & 139.4 & 8.89 \\
\hline 4,0 & 8.68 & 142.10 & 8.73 & 142.1 & 8.73 \\
\hline 1,0 & $8.09(8.14)$ & 151.35 & 8.19 & 151.1 & 8.21 \\
\hline 0,0 & $7.90(7.96)$ & 155.00 & 8.00 & 154.4 & 8.03 \\
\hline
\end{tabular}


the $(7,0)$ band no longer visible and the $(6,0)$ band less well defined. Like the unirradiated sample discussed in Section 3.1.2 the benzene transition bands are present with a lower intensity for both electronic transitions and the vibronic structure of the ${ }^{1} \mathrm{~B}_{1 \mathrm{u}} \leftarrow{ }^{1} \mathrm{~A}_{1 \mathrm{~g}}$ transition are less well defined compared to that of spectrum taken at $20 \mathrm{~K}$. At $90 \mathrm{~K} \mathrm{CO}_{2}$ and $\mathrm{CO}$ have desorbed and interestingly the benzene band has increased in intensity. The ${ }^{1} \mathrm{E}_{1 \mathrm{u}} \leftarrow{ }^{1} \mathrm{~A}_{1 \mathrm{~g}}$ transition shows signs of splitting similar to that observed in the unirradiated sample indicating crystallisation of benzene, however, this is less well defined compared to that of the unirradiated sample and may be due to the bands in the sample being saturated as the sample is thicker than the unirradiated sample. At $140 \mathrm{~K}$ the spectrum looks relatively flat; however, when zoomed in the ${ }^{1} \mathrm{E}_{1 \mathrm{u}} \leftarrow{ }^{1} \mathrm{~A}_{1 \mathrm{~g}}$ transition is present, indicating that benzene is still desorbing at this temperature.

3.2.1 Residue of a $1: 100 \mathrm{C}_{6} \mathrm{H}_{6}: \mathrm{CO}_{2}$ electron irradiated mixture. By $200 \mathrm{~K}$ all of the benzene has desorbed and a residue is left as shown in Fig. 4 and while it displays spectral characteristics similar to that of benzene it has additional structure around $230 \mathrm{~nm}$ not typical of pure benzene. From our work, yet to be published, ${ }^{33}$ on toluene, which is a derivative of benzene, we know that the electronic transitions of toluene redshift compared to that of benzene. Additionally, a study by Hashimoto and Akimoto ${ }^{34}$ showed that when UV spectra of several derivatives of benzene (toluene, p-xylene, mesitylene and durene) in oxygen matrices were taken the absorption maxima of the absorption bands shift from $238 \mathrm{~nm}$ for benzene to $266 \mathrm{~nm}$ for durene (the most substituted ring). This may suggest that the additional feature at $230 \mathrm{~nm}$ is due to the addition of a functional group on the benzene ring, in this case a carboxyl group. Furthermore, the mid-IR results obtained in the study by McMurtry et al. ${ }^{15}$ at $180 \mathrm{~K}$ show evidence of benzoic acid, isophthalic acid and terephthalic acid present, which also leads us to believe that our residue at $200 \mathrm{~K}$ contains benzene

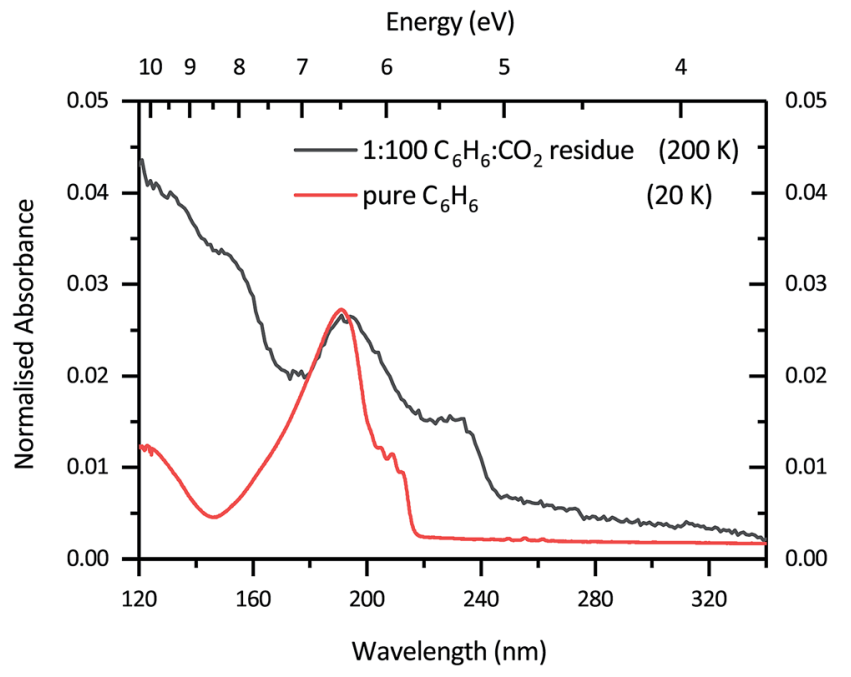

Fig. 4 VUV photoabsorption spectra of a $1: 100 \mathrm{C}_{6} \mathrm{H}_{6}: \mathrm{CO}_{2}$ mixture which was irradiated with $1 \mathrm{keV}$ electrons for $180 \mathrm{~min}$ and annealed to $200 \mathrm{~K}$ (black) to form a residue compared with pure benzene (red) at $20 \mathrm{~K}$. The pure benzene spectrum at $20 \mathrm{~K}$ has been normalised to the peak height at $\lambda=190 \mathrm{~nm}$ of the $1: 100 \mathrm{C}_{6} \mathrm{H}_{6}: \mathrm{CO}_{2}$ residue. derivatives. However, further studies on benzene derivatives in the VUV are still required for more definitive identification of products as such data, to our knowledge, is not available in the literature.

\section{Conclusion}

We have presented the results of the first vacuum ultraviolet spectroscopic study of the interstellar ice analogue of a $1: 100$ $\mathrm{C}_{6} \mathrm{H}_{6}: \mathrm{CO}_{2}$ mixture. Benzene is a prototypical, aromatic molecule believed to be present in the icy mantles of interstellar dust where simple molecules such as $\mathrm{H}_{2} \mathrm{O}, \mathrm{CO}, \mathrm{CO}_{2}, \mathrm{CH}_{4}$ and $\mathrm{NH}_{3}$ are known to reside. These icy mantles will be subjected to energetic processing which can alter the composition of the icy mantles and possibly form benzene derivatives which may later be released into the gas-phase through thermal or photoinduced desorption. Benzene has a relatively high photoabsorption cross section in the vacuum ultraviolet part of the electromagnetic spectrum making it an attractive spectroscopic technique to use for the study of interstellar ice analogues containing dilute mixtures of benzene. Characterisation of the interstellar ice analogue before irradiation suggests that when benzene is diluted into $\mathrm{CO}_{2}$ a matrix-isolation effect takes place. This is evidenced through the shift in the ${ }^{1} \mathrm{E}_{1 \mathrm{u}} \leftarrow{ }^{1} \mathrm{~A}_{1 \mathrm{~g}}$ and ${ }^{1} \mathrm{~B}_{1 \mathrm{u}}$ $\leftarrow{ }^{1} \mathrm{~A}_{1 \mathrm{~g}}$ electronic transition towards gas-phase values of benzene compared to that of pure, solid benzene and the change in band profile to resemble a more gas-like character. Benzene derivatives are predicted to form after irradiation of the interstellar ice analogue ${ }^{15}$ and the residue at $200 \mathrm{~K}$ observed in this study shows that a benzene-like structure has formed. However, definitive assignment begs the need for further VUV spectroscopic work of condensed molecular films of potential irradiation products formed as such data has not yet been published.

\section{Conflicts of interest}

There are no conflicts to declare.

\section{Acknowledgements}

The research leading to this result has been supported by the project CALIPSO plus under the Grant Agreement 730872 from the EU Framework Programme for Research and Innovation HORIZON 2020. RLJ acknowledges the STFC for her PhD Studentship under grant no. ST/N50421X/1. AD acknowledges the Leverhulme Trust for her Fellowship under grant no. ECF/ 2016-842. RLJ and AD acknowledge the Open University for financial support. We gratefully acknowledge Prof. Nigel J. Mason for his contribution to resources and transportation of the Portable Astrochemistry Chamber. All data is provided in full in the Results and discussion section of this paper.

\section{Notes and references}

1 J. Chiar, A. G. G. M. Tielens, A. Adamson and A. Ricca, Astrophys. J., 2013, 770, 78. 
2 J. V. Keane, A. G. G. M. Tielens, A. C. A. Boogert, W. A. Schutte and D. C. B. Whittet, Astron. Astrophys., 2001, 376, 254-270.

3 J. Cernicharo, A. M. Heras, A. G. G. M. Tielens, J. R. Pardo, F. Herpin, M. Guélin and L. B. F. M. Waters, Astrophys. J., 2001, 546, L123-L126.

4 S. E. Malek, J. Cami and J. Bernard-Salas, Astrophys. J., 2011, 744, 16.

5 B. A. McGuire, A. M. Burkhardt, S. Kalenskii, C. N. Shingledecker, A. J. Remijan, E. Herbst and M. C. McCarthy, Science, 2018, 359, 202-205.

6 P. Merino, M. Švec, J. Martinez, P. Jelinek, P. Lacovig, M. Dalmiglio, S. Lizzit, P. Soukiassian, J. Cernicharo and J. Martin-Gago, Nat. Commun., 2014, 5, 3054.

7 T. Q. Zhao, Q. Li, B. S. Liu, R. K. E. Gover, P. J. Sarre and A. S.-C. Cheung, Phys. Chem. Chem. Phys., 2016, 18, 34893496.

8 D. S. N. Parker, F. Zhang, Y. S. Kim, R. I. Kaiser, A. Lander, V. V. Kislov, A. M. Mebel and A. G. G. M. Tielens, Proc. Natl. Acad. Sci. U. S. A., 2012, 109, 53-58.

9 D. P. Cruikshank, C. M. D. Ore, R. N. Clark and Y. J. Pendleton, Icarus, 2014, 233, 306-315.

10 S. J. Clemett, C. R. Maechling, R. N. Zare, P. D. Swan and R. M. Walker, Science, 1993, 262, 721-724.

11 S. A. Sandford, Planet. Space Sci., 2002, 50, 1145-1154.

12 V. C. Geers, E. F. van Dishoeck, K. M. Pontoppidan, F. Lahuis, A. Crapsi, C. P. Dullemond and G. A. Blake, Astron. Astrophys., 2009, 495, 837-846.

13 K. E. Smith, M. P. Callahan, P. A. Gerakines, J. P. Dworkin and C. H. House, Geochim. Cosmochim. Acta, 2014, 136, 1-12.

14 C. K. Materese, M. Nuevo and S. A. Sandford, Astrophys. J., 2015, 800, 116.

15 B. M. McMurtry, S. E. J. Saito, A. M. Turner, H. K. Chakravarty and R. I. Kaiser, Astrophys. J., 2016, 831, 174.

16 B. Zuckerman, J. Ball and C. A. Gottlieb, Astrophs. J., 1971, 163, L41-L45.

17 D. M. Mehringer, L. E. Snyder, Y. Miao and F. J. Lovas, Astrophs. J., 1997, 480, L71-L74.

18 S. Pizzarello, Y. Huang, L. Becker, R. J. Poreda, R. A. Nieman and G. C. M. Williams, Science, 2001, 293, 2236-2239.
19 S. Pizzarello and Y. Huang, Meteorit. Planet. Sci., 2002, 37, 687-696.

20 R. W. Hilts, C. D. K. Herd, D. N. Simkus and G. F. Slater, Meteorit. Planet. Sci., 2014, 49, 526-549.

21 S. Pizzarello and Y. Huang, Geochim. Cosmochim. Acta, 2005, 69, 599-605.

22 Z. Martins, J. S. Watson, M. A. Sephton, O. Botta, P. Ehrenfreund and I. Gilmour, Meteorit. Planet. Sci., 2006, 41, 1073-1080.

23 L. Remusat, S. Derenne and F. Robert, Geochim. Cosmochim. Acta, 2005, 69, 4377-4386.

24 A. Dawes, N. Pascual, S. V. Hoffmann, N. C. Jones and N. J. Mason, Phys. Chem. Chem. Phys., 2017, 19, 27544-27555.

25 N. J. Mason, A. Dawes, P. D. Holtom, R. J. Mukerji, M. P. Davis, B. Sivaraman, R. I. Kaiser, S. V. Hoffmann and D. A. Shaw, Faraday Discuss., 2006, 133, 311-329.

26 L. Zhou, W. Zheng, R. I. Kaiser, A. Landera, A. M. Mebel, M.-C. Liang and Y. L. Yung, Astrophs. J., 2010, 718, 12431251.

27 M. Bouilloud, N. Fray, Y. Bénilan, H. Cottin, M.-C. Gazeau and A. Jolly, Mon. Not. R. Aston. Soc., 2015, 451, 2145-2160.

28 M. H. Palmer, T. Ridley, S. V. Hoffmann, N. C. Jones, M. Coreno, M. de Simone, C. Grazioli, M. Biczysko, A. Baiardi and P. Limão-Vieira, J. Chem. Phys., 2015, 142, 134302.

29 D. Drouin, A. R. Couture, D. Joly, X. Tastet, V. Aimez and R. Gauvin, Scanning, 2007, 29, 92-101.

30 A. Dawes, N. Pascual, N. J. Mason, S. Gärtner, S. V. Hoffmann and N. C. Jones, Phys. Chem. Chem. Phys., 2018, 20, 1527315287.

31 G. Cruz-Diaz, G. M. M. Caro, T.-J. Chen and T.-S. Yih, Astron. Astrophys., 2014, 562, A120.

32 G. M. M. Caro, A. Jiménez-Escobar, J. Á. Martín-Gago, C. Rogero, C. Atienza, S. Puertas, J. M. Sobrado and J. Torres-Redondo, Astron. Astrophys., 2010, 522, A108.

33 R. L. James, J. Dezaley, N. C. Jones, S. V. Hoffmann and A. Dawes, unpublished work.

34 S. Hashimoto and H. Akimoto, J. Phys. Chem., 1989, 93, 571577. 